Cuad. invest. hist. Brocar n. 16 (1990). Págs. 85-91.

\title{
UN INVENTARIO DEL CASTILLO DE CORNAGO EN 1497
}

\author{
José G. Moya Valgañón
}

\begin{abstract}
RESUMEN.- Se comenta un inventario de 1497 que muestra como el castillo de Cornago fue residencia señorial a fines del siglo XV.

RESUME.-Un inventaire de 1497 montreque le château de Cornago fut residence seigneuriele a la fin du XV siècle. On l'analyse.
\end{abstract}

Palabras clave: Cornago, arquitectura militar medieval, mobiliario medieval.

No conocemos demasiada documentación escrita sobre los castillos de esta tierra. Hace poco tiempo Cantera Montenegro ${ }^{1}$ publicaba un inventario de la dotación militar del castillo de Briones, que ya diera a conocer el marqués de Laurencín en $1898^{2}$, aprovechando para hacer diversos comentarios sobre Briones como plaza fuerte en la Edad Media, a veces con no demasiado acierto.

Por ello me parece oportuno traer aquí a colación este acta notarial sobre el de Cornago, del que pueden extraerse muy diversas conclusiones o sugerencias.

De entrada nos da a conocer un señor de Cornago que no está en la lista proporcionada por el padre Ovejas ${ }^{3}$, al que le faltaban noticias entre 1460 y 1511 , saltando desde doña María a un don Alvaro de Luna. Posiblemente el don Pedro que en nuestro documento se menciona debió ser hijo de la anterior, como también su hermano Juan, señor así mismo de la villa con anterioridad al parecer ${ }^{4}$, si no de derecho, si de hecho, pues se permitió empeñar el señorío al conde de Aguilar.

\footnotetext{
1 El castillo de Briones (La Rioja) a mediados del siglo XV (ESTUDIOS MIRANDESES, 2, 1982, págs. 87-104):

2 F. R. de UHAGON: Ordenes militares. Discursos leidos ante la Real Academia de la Historia en la recepción pública de ..., Madrid, 1898, págs. 23-24, nota.

3 El castillo de Cornago (BERCEO, V, 1950, págs. 523-546). Tampoco figura en el menos interesante de J. M. PALACIOS SANCHEZ: El Célebre y Caballeroso linaje de los Luna, en su Entronque con el Señorio de la Villa Riojana de Cornago... (BERCEO, 1980, pảgs. 55-78).

$4 \mathrm{El}$ señorio de Cornago debió ser muy discutido a los sucesores del condestable don Alvaro a lo largo de la segunda mitad del siglo XV. Don Alvaro lo constituyó en el mayorazgo establecido a favor de su hija María de Luna y su marido y primo Juan de Luna en 1440, junto con Jubera (OVEJAS: op. cit.) y hubo de ser confirmado pocos días después de su
} 
Lo más interesante quizá es la enumeración de bienes que conforman la dotación del castillo como una morada palacio en la que vivía el señor aunque a través de ella no acabemos de hacernos una idea completa de como estaba dispuesta.

Desde luego existen dos dormitorios. Uno hay en la torre cuadrada, la situada al norte, donde aparece un arca con calzado (barceguíes, alcorques, servillas), ropa (jubona) y aderezos, incluidos cuchillos, (cinto con antojos en una bolsa, más cuatro cuchillos) y un poco de dinero, otra recubierta de cuero con función de archivo, que podemos interpretar como escritorio, varios elementos de armadura o arnés (capacetes con baveras, musiques, quijotes, medios gocetes, guardacetes y pavesina o escudo chico), más dos catres, que apoyarían en las cuatro puntas que se mencionan, una cama y varios paramentos, alguno de los cuales corresponde a ella, como las dos antepuertas y la alfombra-cobertor, otros serían para los catres, camas plegadizas como de viaje, y alguno simplemente cerraría acceso o recubriría pared. De ellos, unos presentaban como decoración eles que se referirían al apellido Luna y acaso alguno de los de arboleda o figuras sería tapicería en lugar de bordado.

Otro estaba en la torre redonda, probablemente la del sur. En el retrete se hallaba la cama, con sus colchones y ropa, incluido cobertor de piel (pellón), y otro, probablemente, de tipo bancal, en tapicería (paño francés), los paramentos con las iniciales de Juan y el calentador. Pero allí había también material de estudio, como dos libros, casi con total seguridad de Andres de Li (Repertorio y Pasión Trobada), acaso de los impresos en Zaragoza por Pablo Harus en 1492 y 1494, o la escribanía de sobremesa.

Otros objetos nos indican que era estancia muy utilizada y habitual, asi los candeleros, los contenedores (alforjuelas, barjuleta, cajón), los bordones o la botillería, quizá de botica. Y lo mismo sugiere el contenido de la antecámara o salilla, donde, además de un arca con diversas ropas de calidad y otra con ropa de cama, hay una mesa plegable, un brasero y almohadas de tapicería de Tournay.

ejecución, el 15 de junio de 1453, por el propio Juan II a la misma María (A.H.N., Osuna, leg. 2189,n.ำ5). Al desterrar Enrique IV a Juan de Luna en 1459 y posteriormente confiscar sus bienes a fines de 1461, se consideraría perdido el señorío, lo que obligaría al propio don Juan a ocupar por la fuerza en ese mismo año la villa y fortaleza (Memorias de don Enrique IV de Castilla, II, Madrid, 1835-1913, n.․ LXVIII). Los Luna no fueron bienquistos en la corte de Enrique IV, en la que, a cambio, tenían poderosos rivales que deseaban sus propiedades, tales como el propio marqués de Villena o el arzobispo de Toledo, don Alonso Carrillo. Este aspiraba al señorío de la fortaleza y villa de Cornago, pues en su jurisdicción ya tenía un pequeño establecimiento. Así, en 1462, en las paces entre Castilla y Navarra, se estipulaba que la tenencia de las fortalezas de Jubera y Cornago fuese para él. Obtuvo una venta del señorio por parte de doña María de Luna, en presencia de su hijo Juan, que esta declaraba forzada y contra su voluntad en 1465, y en 1468 lograba que la futura reina Isabel le prometiese la fortaleza y villa. En tanto, Enrique IV llegó a conceder la tenencia del castillo, y luego en 1464 el señorío, a Juan de Beamonte. Por otro lado, también los Ramírez de Arellano, con propiedades dentro del término de Cornago y con el que lindaban sus estados, parecen aspirar a aumentarlos (OVEJAS: La casa Carrillo en tierra de Cornago, BERCEO, XV, 1960, págs. 393-404).

En numerosas ocasiones debió reclamar doña María de Luna el señorio, señal de que no lo disfrutaba en paz. En 1467, a 10 de marzo, se lo restituía Enrique IV. De 1473 hay una sentencia de los alcaldes de Cornago contra unos traidores a doña Maria que pretendieron vender y entregar el cortijo de Igea al arzobispo de Toledo. En 3 de enero de 1483 los Reyes Católicos ordenan al concejo que la tengan por su señora. En 24 de setiembre de 1484 mandan a Rodrigo de Cornago que devuelva a ella y a sus hijos lo que les cogió al tomar la villa y fortaleza diciendo que iba de parte de la reina. En 30 de enero de 1485 mandan al concejo que acuda a doña María con todos sus pechos y derechos. De 1486 hay dos cédulas reales para que se la tenga por señora de Cornago. De 15 de febrero hay otra petición de Juan de Luna para que la reconozcan como señora y se castigue a los vasallos desobedientes (A.H.N., sección Osuna, Leg. 2189 , nums. 6, 7, 8, 9, 10, 12, y Leg. 2183, n.ำ 4). Todo ello me refuerza la idea de un gran deseo hacia el dominio de unas tierras muy ricas en ganadería, pero también en cereal, huerta y frutal, además de mineria, cuyos señores habían perdido fuerza y, sobre todo, apoyo en la corte. Probablemente no son sỏlo familias rivales las que desean percibir las rentas de tan extenso territorio, sino síntomas de aspiración de mayor libertad de los vasallos e incluso disputas entre los propios sucesores de don Alvaro. Por el documento publicado parece que don Juan había detentado el señorio ilegalmente, siendo así que es al que hemos encontrado en otros actos al lado de su madre. 
El confesonario no sé si se trataría de mueble destinado al efecto o de libro, guía de confesión. Pero en uno u otro caso parece indicar, junto con los contenedores de vidrio, que serían las piezas donde pasó don Juan sus últimos tiempos, si efectivamente éstos estaban dedicados a contener medicinas y no vino simplemente, lo que podría suceder también con los saleros. El peso para pesar oro puede haber sido utilizado con estos fines, para dosificar, pero también puede significar un gusto por controlar la economía, junto al libro de cuentas, en una casa donde no debía ser muy boyante a pesar del tono que le presten las colgaduras del apellido o el repostero con yes de Juan, los almohadones de tapicería o la mesa que, por la descripción, más parece de patas abatibles que de tablero plegado, amén de los libros ricamente ilustrados, si efectivamente son de los editados por Hurus. Ha de notarse el aprecio en que don Juan tenía ciertos aparejos de sus mulas que los hacía dormir consigo.

En la misma torre había al parecer una cocina bien provista de efectos para cocinar (trebedes, sartenes, parrillas, asadores, que serán espetones, cucharas, olla y calderas) y de vajilla de cerámica (platos, escudillas, ollas, cántaros, jarros, plateles) incluída la sanitaria (servidores). A destacar entre la cerámica lo de hechura de Herce, que serían de las producidas por los moros de esta localidad 5 .

En la propia cocina se menciona una silla de cuero, dos arcas, un brasero y un candelero, indicio de su utilizacion como estancia.

En esta torre estaba también el poco armamento, más bien defensivo, que se cita (paveses, corazas y arca de pólvora) y al pie de ellas la bodega, con tres cubas para ciento cincuenta y cinco cántaras, dos tinos y un pisador, más otros útiles de vendimia. No es imposible que, según se ha puesto de manifiesto en la restauración del edificio, tal bodega sea el hueco excavado en la roca aparecido hacia ese ángulo sureste pero fuera de la torre, que presenta arriba un boquete desde el que podía colar el mosto de las tinas a la bodega. Aunque se considera nevera, la presencia de rebanco corrido y escalera de bajada me hace pensar en esta utilización.

Menos interés tiene el resto del inventario. La torre vana considero que es la mayor y más baja, la única con acceso a la primera planta desde el patio, pues las otras lo presentan a la altura de la barbacana. En ella había una cuba de ochenta cántaras y herramientas agrícolas o de carpintería. Si a ella corresponde la sala yusana, tendriamos, de acuerdo con la tradición alto medieval, que su planta baja se dedicaba a almacén de provisiones y otros productos.

Para entonces ya estaban construidas las dependencias del interior del patio que acusan las dos líneas de mechinales del muro actualmente y a que se referirían las expresiones, casas o casa de más adentro, con cocina baja y sala mediana.

De lo contenido aquí, poco, habríamos de destacar, aparte de los comestibles, la mesa, el banco y la silla. La última, de costillas, sería del tipo tan extendido en la Baja Edad Media, a base de varios montantes en equis plegándose por su eje. La primera, del tipo más común, con un tablero sobre dos apoyos de tipo borriqueta, los moros, para colocar junto al fuego, quizá tuvieron forma de caballito. En cuanto a las retrancas, nos indican, como los aparejos, que la casa había visto tiempos más desahogados, pues la hacanea no se cita entre los animales de montar, sino simplemente una mula y un rocín.

5 Cfr. J. G. MOYA VALGAÑON: Mudéjar en la Rioja (ACTAS DEL I SIMPOSIO INTERNACIONAL DE MUDEJARISMO, Madrid-Teruel, 1981, pags. 211-219). 
En esas casas debían estar las cuadras, con los animales que se mencionan, y la capilla con los retablitos de la Anunciación y Santiago, devociones harto frecuentes por entonces aunque acaso la segunda tuviese su origen en los buenos tiempos del abuelo don Alvaro, maestre de esa orden.

Diversas conclusiones generales podemos sacar del conjunto del documento.

Acaso la primera sea la decadencia económica a que se había visto reducida la casa, o al menos don Juan, obligado a empeñar el señorío a su poderoso vecino el conde de Aguilar. Los Ramírez de Arellano habian sido apoyados por don Alvaro, como testimonia la Crónica de éste ${ }^{6}$, ulteriormente debieron emparentar, como sugiere el pleito de 1520 en la Chancillería, con una Mencía de Frías que debió estar casada con Alonso Ramírez de Arellano, conde de Aguilar ${ }^{7}$. Decadencia que habrá de explicarse en los tormentosos tiempos de la segunda mitad del siglo XV que dificultaron la percepción de derechos señoriales de un territorio relativamente rico en lo agrícola y lo ganadero, independientemente de las rentas directas que tendría en sus tierras el señor. Esa escasez se refeleja en el poco ganado, pero también en el resto de la casa. Vemos que casi todo está viejo y roto y que las cinco piezas de plata que se mencionan, dos jarros, dos tazones y parte de un salero, están empeñadas. Pero, aún así, queda una idea de la adecuación interior de este tipo de casas señoriales, con predominio de textiles, en muchos casos de importación, recubriendo paredes y muebles. Estos son escasos. Dos sillas y un banco se mencionan, pero no hay que olvidar que el conjunto arquitectónico posee tres ventanas de asiento y que probablemente en las casas habría poyos de obra. De obra es también el aparador del corredor, uno de los huecos aparentes que se ven en el muro suroeste. En cambio, la vajilla o la dotación de útiles de cocina parece más que suficiente, aun dadas las dos que habia. Y suponemos que por entonces en el castillo vívían dos Juan y Brianda de Luna, hija o esposa de él.

Que su destino en ese momento era morada lo justifica de sobra el escaso número de armas en él existentes, suficientes sólo para equipar a algún villano para ronda o vela, aportando éste lo ofensivo.

Algún comentario merecería acaso el vino, cuya cantidad manifiesta cosechas mayores o más abundante plantación que la ahora (o en el siglo pasado) existente, además de especializada, (tinto bueno, de medias, blanco). También los libros, sobre todo el Repertorio de los tiempos, que nos podría ayudar a comprender la mentalidad de don Juan. Pero sería extenderse mucho todo ello, aparte de que de lo último sin más datos, nunca podríamos saber si es que era aficionado a la astrología, a la mitología o, simplemente, y es acaso lo más probable, lo utilizaba como Calendario Zaragozano, como agricultor que era.

6 Crónica de don Alvaro de Luna, condestable de Castilla, maestre de Santiago, ed. y est. J. de M. CARRIAZO, Madrid, 1940, pág. 449.

7 Así parece sugerírnoslo una de las noticias que aporta COOPER (Castillos señorales de Castilla de los siglos XV y XVI, Madrid, 1981, II, pag. 872). Doña Mencía, además de parienta, era señora de parte de Robres, que lindaba con Jubera, la otra villa importante del señorío de los Luna.

La documentación inédita aquí recogida ha sido localizada en el A.H.N. por doña María Vitoria Tejada, dentro del Plan de Investigación sobre Arquitectura civil en La Rioja. 


\section{INVENTARIO DE LOS BIENES RELICTOS DE DON JUAN DE LUNA Y SE- CUESTRO DE LOS MISMOS POR SU HERMANO DON PEDRO.}

A.H.N.; Osuna, Leg. 2189, n.. 13

En la villa de Cornago, a doze dias del mes de henero año del nasçimiento del Nuestro Señor Ihesu Christo de mill e quatroçientos e noventa e siete años, en el castillo e fortaleza de la dicha villa, estando ende Diego Rruis e Pero Benito alcaldes de la dicha villa en presencia de nos Diego Peres de Aguilar e Alonso Peres de Aguilar, escribanos e notarios publicos del rrey e rreina nuestros señores e de los testigos de yuso escriptos, paresçió y presente el señor don Pedro de Luna, señor de la dicha villa de Cornago. El qual dixo que, por quanto a Dios nuestro señor a plazido de levar desta presente vida al señor Juan de Luna su hermano que santa gloria aya, el qual falesçió ayer miércoles en la noche que se contó a honze dias deste dicho mes y su merced avia quedado en la dicha fortaleza como de presente estaua, en la qual estauan e avian quedado çiertos bienes muebles que heran del dicho señor Juan de Luna e fuera del mayorazgo de la dicha villa e fortaleza que a él como a su heredero legítimo pertenesçe.

Por ende, dixo que daua e dio e entregaua e entrego de presente a los dichos alcaldes las llaves todas de la dicha fortaleza como de las casas e torres e cofres e arcas que en ellas estauan e les rrequería e rrequirió en la mejor forma e manera que pudia/e de derecho deuia que miren e caten todas las dichas torres, casas, cofres e arcas que en la dicha fortaleza estauan e los bienes todos, joyas, oro e plata que asi fallaren en todo ello e que el dicho señor Juan de Luna dexo e le perteneçen e heran e son suyos propios los fagan escriuir y echar por ynventario por ante nos los dichos escribanos e que lo pidia e pidió por testimonio signado e por en descargo suyo. E los dichos alcalde dixeron que oian lo que disia su merced del dicho señor don Pedro de Luna y que estauan y heran prestos de fazer aquello que con justiçia deuan. E fasiendo lo que deuen luego rresçibieron e tomaros en su poder todas las dichas llaues que asi el dicho señor don Pedro les avia dado. E luego miraron e cataron todas las dichas torres, casas e cofres y arcas que en la dicha fortaleza estauan e se fallaron e por ante nos los dichos escribanos fisieron escriuir y echar por ynventario todos los bienes muebles e cosas que en todo ello fallaron que el dicho señor Juan de Luna que santa gloria aya dexó al tiempo de su finamiento y que a su merçed pertenesçian por dicho e confesion de los que en la dicha fortaleza estauan. E lods dichos tales bienes que así se fallaron son los que se siguen:/

Primeramente estaua en la torre quadrada una arca blanca en que se tenían y estauan en ella tres pares de borzeguies e tres pares de alcorques e tres pares de sirvillas e vna jubona de paño e dos pares de cuchillos $\mathrm{e}$ vn çinto blanco guarneçido de plata en que tenía vna bolsa con vnos antojos e trese rreales de plata e siete ardites. Estauan en la dicha torre dos pares de puntas e dos catres. E otra arca con çiertas e muchas escripturas que estaua guarneçida de cuero vieja. Mas vnos paramentos de vnas eles blancas viejo. E otros paramentos de cama colorados e broslados viejos e de arboleda e figuras. Mas estaua en vna sera dos capaçetes con sus baueras e dos pares de quixotes e vn par de musiques e vnos medios goçetes e dos pares de guardaçetes e vna pauesina. E vna alhonbra vieja en vna cama que estaua en la dicha torre con dos antepuertas viejas e rrotas.

En la torre rredonda nueve paueses e vnas coraças e vna arca con poluora. Hallóse en el rretrete de la salilla donde su merced dormía dos colchones e vn paño francés viejo e vna manta blanca e dos guarniçiones de mula de cuero negras e dos pares de çinchas e vn pellón de la/ cama e dos pares de alforjuelas e vna barjuleta e vn caxon e vnos candeleros e vna dozena de madexuelas de bramniate e vn escalentador e vna Valeriana e el Repertorio de los tiempos e Vita Christi con la Pasion trobada. E ocho çestas e vna gamella e nueve rredomas e taças de vidrio quebradas e sanas. $E$ vnas escrivanias de asiento. $E$ dos bordones con sus cabeças. $E$ vn paramento con vnas yes viejoe rroto. E en la salica dos almohadas de arboleda de Tornay. E vn jubón de hustan negro con mangas de rreaso. E vn rrepostero viejo de vnas yes negras. $\mathrm{E}$ dos paramentos viejos e rrotos. E vn jubón de damasco negro. $\mathrm{E}$ vn peso de pesar oro. $\mathrm{E}$ çiertas cuerdas de viuela. $\mathrm{E}$ vn confesionario. E vn sayo de pardillo negro de Aragón. E vn libro de cuentas. E vn tabardo de Contray frisado. E vn salero de estaño. E otro de palo. E vna arca de nogal grande en que estauan las dichas rropas. E vna mesa con su pie de vnas visagras de aes de alatón. E en otra arca blanca siete sauanas rresias. E vn brasero grande viejo e quebrado.

E en la cosinilla de arriba/ vna olla de cobre. E vnas treudes e dos sartenes, E dos assadores. E dos cucharas de hierro. E media dozena de platos de tierra e media dozena de escudillas e ollas quebradas todo de tierra. E vn candelero pequeño e vn brasero e vn badil. E dos arcas de haya vasías. E vna silla de cuero. En el entresuelo 


\section{JOSE G. MOYA VALGAÑON}

quatro asadores de fierro e vnas parrileas e dos sartenes de fierro. E vna caldera vieja. E otra caldera vieja mayor. E vn caldero grande. E vna dozena de cántaros e catorze jarros e çiertos plateles e ollas de Herçe, todo de tierra. E tres panderos. E dos cribas e harneros. E quatro seruidores de tierra. E una olla de tierra grande. $\mathrm{E}$ dos cuchares de fierro. $\mathrm{E}$ tres costales viejos.

En la bodega vn tino de ochenta cargas e vna gamella enbusadera. E otro tino de hasta quinze o dies e ocho cargas. E vna cuba vasía de çinquenta e çinco cantaras. E otra cuba de ochenta cantaras llena de vino de a medias. E otra cuba de quareinta cántaras llena de vino tinto bueno. E otra cuba vasia de veinte cántaras. $E$ vn pisador ençima de la bodega de dos cargas. E quatro conportas. E vn par de cuévanos.

En la torre vana una cuba de fasta ochenta cántaras llena de vino/blanco. E vn par de açadones. Evna açada. $E$ vn par de açuelas. $E$ vn destral quebrado. $E$ tres serones. $E$ vnas angarillas rrotas.

En la sala yusana quinze fanegas de çebada e vna arroua de cáñamo. E seis botarrones viejos e rrotos. E treze tablas de pino e rroble.

E en la casa de mas adentro vnas arritrancas de hacanea blancas. E çinco fanegas de çeuada.

E en la cozina baxa vn gamellón e vn destral quebrado.

En la sala mediana vna mesa blanca con sus pies e vn vanco. E seis toçinos e ocho quartos de carne salada. E vna silla de costillas. E dos moros de hierro. E dos cántaros viejos.

En el aparador del corredor seis toçinos e mas otros seis toçinos.

En la capilla dos rretablillos de la Salutaçion e otro de Santiago. Mas vn almud e vna hoz de podar vieja quebrada. E vna galleta de palo. E vna mula con su silla e freno. E vn rroçin de dos manos con su silla e freno. $E$ tres azémilas con sus albardas e aparejos. $E$ vn borrego. $E$ vna puerca con siete cochinos.

Los quales dichos bienes, segund dicho es, se fallaron en la dicha fortalesa de los que heran del dicho señor Juan de Luna propios. E non/ se fallaron otros algunos, saluo otros e çiertos bienes e joyas e cosas que quedaron de fuera. Que la señora doña Brianda de Luna, sobre juramento que fiso en forma deuida de derecho, e Ios dichos alcaldes se lo tomaron sobre la señal de la crus corporalmente con su mano derecha tañida e a las palabras de los Santos Euangelios donde quier que fuesen escriptas, dixo e juro que heran e son suyos propios e por tales suyos los a tenido e tiene de mucho tiempo antes acá que el dicho señor Juan de Luna su señor finase. Y así aquellos que ella dixo que heran suyos propios quedaron de fuera deste sobre dicho ynventario, segund lo depuso e declaró por su boca so cargo del dicho juramento que fizo. E así mismo el dicho señor don Pedro de Luna dixo que prometía e prometió e protestaba e protestó que, si de algunos otros bienes e cosas él supiese e fallase que heran e pertenesçian e pertenesçen al dicho señor Juan de Luna, de lo desir e declarar cada e quando que lo supiese e así lo pidía e pidió por testimonio.

Testigos que fueron presentes Juan Peres de Aguilar escribano e Pedro Hordoñes e Ferrand Gómes e Rremir Gonçáles, vesinos de la dicha villa de Cornago./

E después desto, en la dicha villa de Cornago, a treze días del dicho mes de henero año suso dicho, en el dicho castillo e fortalesa, en presençia de nos los dichos escribanos e de los testigos de yuso escriptos, los dichos Diego Rruiz e Pedro Benitho alcaldes dexaron e pusieron en poder e depósito e depositaron todos los suso dichos bienes en el sobredicho ynventario contenidos e escriptos en poder e depósito del dicho señor don Pedro de Luna para que su merced así los tenga en su poder e dé cuenta dellos a quien ge lo pidiere e de derecho ge la deuiere dar. E asi su merced del dicho señor don Pedro de Luna dixo que rresçibia e tomaua e tomó de los dichos alcaldes en su poder e depósito todos los dichos bienes en el dicho ynventario contenidos y escriptos e se obligaua e obligó con su persona e bienes, muebles e rraizes, avidos e por aver, donde quier que los aya e deua aver de derecho, de dar buena cuenta de todos los sobredichos bienes e de cada cosa e parte dellos a quien de derecho e justiçia la deuiere dar. Para la qual dixo que daua e dió e otorgó poder conplido.../...

Testigos que fueron presentes Juan Perés de Aguilar escribano e Pero Hordoñes e Ferrand Gomes, vesinos de la dicha villa de Cornago.

E luego después desto, este dicho día en el dicho castillo e fortalesa, estando ende los dichos alcaldes, en presençia de nos los dichos escribanos e de los testigos de yuso escriptos, paresçió y presente el dicho señor don Pedro de Luna. El qual dixo que, por quanto el dicho señor Juan de Luna que santa gloria aya, su hermano, le tenía e tiene su mayoradgo o parte dél enpeñado en poder del señor conde de Aguilar por quantía de tresientos mill maravedis que su señoría sobre ello le enprestó, non lo pudiendo faser nin empeñar de derecho e justiçia, lo qual el non es tenido nin obligado a pagar nin cosa alguna dello, por ende dixo que por virtud de lo susodicho el ponia e puso e fasía e fizo enbargo e sequestraçión en todos los susodichos bienes en el dicho ynventario contenidos e en otros quales quier bienes, asi muebles comorrayzes/ que paresçieren ser e pertenesçer del dicho señor Juan de Luna. E protestaua e protestó de los tener ansí fasta que él sea conplido de justiçía de lo susodicho e del dicho enpeñamiento. 
El qual dicho enbargo e sequestraçión dixo que fasía e fizo en la mejor forma e manera que pudía e de derecho deuía e non en más nin allende e que lo pidia e pidió por testimonio signado para en guarda de su derecho. E los dicho alcaldes dixeron que oían lo que el dicho señor don Pedro de Luna disía y que estau an $y$ heran prestos de faser lo que de justiçia deuiesen.

Testigos que fueron presentes, los susodichos.

E despes desto, en la dicha villa de Cornago a veint e dos días del mes de hebrero año susodicho, en el dicho castillo, en presençia de nos los dichos escribanos e de los testigos de yuso escriptos, paresçió y presente el dicho señor don Pedro de Luna, el qual dixo que:

Por quanto al tiempo que el sobre dicho ynventario de los sobredichos bienes del dicho señor Juan de Lu na su hermano, que/ santa gloria aya, se fiso, el avia prometido e protestado que, si algunos otros bienes e cosas él fallase e supiese del dicho señor Juan de Luna, sin los contenidos en el dicho ynventario, que los diría e magnifestaría, por ende que, por lo que prometió e por descargo de su conçiençia, desia e magnifestaua e magnifestó ante nos los dichos escribanos que él avía seido informado e sabidor como Miguel Garçia d'Entramas. Aguas tenía enpeñado del dicho señor Juan de Luna vn jarro e vn taçon de plata. E Gil Martínes de Valdecantos, vesino de Yanguas, otro jarro e otro taçón. E Pero Sanches de Yanguas vna pieça de vn salero de plata. Pero que él no sabia de que peso hera ninguna de las dichas pieças nin sabía por quanto estauan enpeñadas. $Y$ que por el presente non sabia nin se le acordaua de otra cosa alguna.

Testigos que fueron presentes Aluar Gutièrrez de Viruega e Diego Çeruero e Alonso de Varoja, vesinos de la dicha villa de Cornago.

E yo el dicho Diego Péres de Aguilar, escribano e notario público del rrey e rreyna nuestros señores suso dicho, fui presente a todo lo que dicho es, juntamente con el dicho Alonso Péres de Aguilar escribano, e en vno con los dichos testigos e por mandado de los dichos alcaldes este público ynstrumento de ynventario e sequestraçión e enbargo, segund que ante nosotros los dichos escribanos pasó, y yo el dicho Diego Péres lo escreui e saqué en pública forma. El qual va escripto en seys fojas de papel de quarto de pliego con ésta en que van nuestros signos e en fin de cada plana van dos señales e rrúbricas de las de nuestros nonbres. E por ende fis aquí este mio sig+no en testimonio de verdad.- Diego Péres.

E yo el dicho Alonso Péres de Aguilar, escribano e notario público del rrey e la rreyna nuestros señores en la su corte e en los sus rregnos e señorios, fui presente a lo que dicho es en vno con el dicho Diego Péres de Aguilar escribano e con los dichos testigos e por ende fis aquí este mío sig+no en testimonio de verdad.Alonso Péres.

Presentada esta escriptura sinada en Valladolid ante los señores oidores, estando haziendo avdiençia pública, a onze días del mes de agosto de mill e quinientos e veinte años,/ por Antón Dorón en nonbre de don Alvaro de Luna, su parte, para guarda de su derecho para en el pleito que trata con doña Mendía de Frias, estando presente Juan López de Arrieta su procurador, al qual los dichos señores mandaron dar traslado e que rresponda para la primera avdiençia.+ 
